been overlooked. More elaborate hypotheses may be needed, but not until the simpler have been disproved.

Grantchester, Cambridge, April $10 . \quad$ W. Bateson.

P.S.-A reviewer declares (Nature, April 9) that the data in this case are "by no means easy of interpretation," on what hypothesis I know not; and that "much of the evidence is prima facie in favour of ancestral inheritance." It is scarcely too much to state that in each set of matings the distribution (r) of pink and dark-eyed, (2) of coloured and albino coats, (3) of "waltzers" and non-waltzers, is in punctilious agreement with Mendelian prediction. The variety of colour in the first cross I have dealt with. Knowing something of the recent history of fancy mice, two kinds of grey in this generation cause me no surprise. In the whole evidence 1 can find only three real difficulties, all surely of minor importance. One is named in my letter. The second is the occurrence of three dark-eyed fawnyellows in the offspring of first crosses. The third is the scarcity of yellows in the offspring of hybrids $\times$ albinos. If the individuality of the parents were declared, two, perhaps all, of these points could be cleared up. I am not acouainted with any other conception of heredity which elucidates any part of the facts.

Experiment to Illustrate Precession and Nutation.

THE following account of a simple experiment may be of interest to some of the readers of NATURE. The common peg-top and tee-totum are commonly referred to as affording a good example of the phenomenon of precession. I do not think that it is generally known that the motion of nutation can be beautifully shown by the same simple means. Sir John Herschel says in his "Outlines of Astronomy" that the motion of precession can be shown by " that amusing toy, the te-to-tum, which, when delicately executed and nicely balanced, becomes an elegant philosophical instrument." If, however, the teetotum is not perfectly balanced

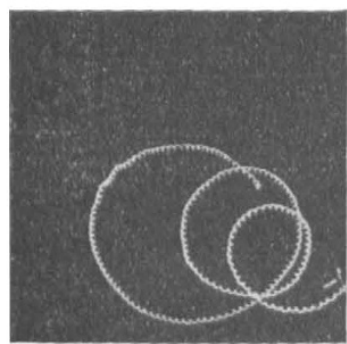

FIG. I - Trace made by imperfectly balanced watch uheel spinning on its axis, illustraing precession and nutation. we have realised the conditions for showing nutation also. If the earth were perfectly homogeneous and undisturbed by any outside irregularity, there would be no nutation. In the same way a tee-totum will not exhibit the motion of nutation if it be perfectly balanced. When, however, one side is made heavier than the other we obtain the phenomenon of nutation. The magnitude of the nutation increases with the extra weight. A series of experiments was made by spinning

a small clock wheel on its axis. The best way to see the result is to spin the wheel on a white plate which has been smoked. The trace thus obtained may be studied perfectly. In order to get a permanent record, the wheel was made to spin on a piece of clear glass which had been slightly smoked. The record thus obtained may be used as an ordinary negative, and prints obtained on sensitive paper in the ordinary way. With a little care very beautiful and instructive results may be obtained. The little apparatus may also be projected on the screen, and the actual formation of the curve exhibited.

Clongoweswood College, Sallins, Co. Kildare.

\section{Distribution of $P_{1}$ thc phora.}

IN October last, I found an old-established paddy-field near Tanabe, the bottom of which, to the extent of several tens of feet every way, was luxuriantly grown with the Pithophora Oedogonia, Wittrock, var. Vaucherioides, Wolle, with resting spores yet incompletely formed. The locality is some sixty miles south of Wakayama Shi, where I had gathered the same with full spores, October, I9or (see NATURE, vol. $1 x v i$, pp. 279, 296). The occurrences of the alga in such distant places seem to prove that it is indigenous to Japan. The Floridan specimens I collected in $1891-92$ were with spcres mature in the months of June and July.

Kumagusu MinaKata.

Mount Nachi, Kii, Japan, March io. No. 1747 . VOI.. 677

\section{PEDIGREES.}

$T \mathrm{HE}$ trouble of compiling pedigrees and their unmanageable size led me to devise a method of recording relationships in a form suitable to my own particular wants. As it promises to answer exceedingly well, and to be of more extended utility, I venture to publish it.

The system of relationships between those who live or have lived in a long-established community is wide in extent, of indefinite depth, and interlaced in all directions. The problem is how to arrange its records so that when any individual is selected as a point of departure, it shall be easy to trace his relationships in every direction, whether ascending, descending, or collateral, so far as materials exist. The representation of such a system is wholly beyond the powers of a chart, but its object can be attained by breaking it up into what will be called " Family Groups," each of which slightly overlaps those with which it is immediately connected. A family group, in the sense used here, consists of (I) a parental couple, (2) all their sons and daughters, (3) the wives and husbands of them. Their names are supposed to be written on one page of a register, and the group, as a whole, to be defined by the No. of that page. The group is also defined and indexed under the joined surnames of the parental couple. I subjoin three specimen groups, but in a much abbreviated form for the sake of compactness,

Family Groups.

\begin{tabular}{|c|c|c|c|c|c|c|}
\hline John & Gor & & $16 \mathrm{Fel}$. & & $3^{1}$ & 101 \\
\hline Amy & Mye & & 24 Mar. & & 43 & \\
\hline Fred. Gore & & IOI & Mary Drew & $\cdots$ & I 44 & 205 \\
\hline George Gore & $\ldots$ & IOI & Jane Boyle... & $\ldots$ & I 36 & 211 \\
\hline Ellen Gore ... & $\ldots$ & IOI & John Piers ... & $\ldots$ & 105 & 237 \\
\hline Susan Gore $\ldots$ & $\ldots$ & roI & Unmar. & & - & - \\
\hline Steph. Gore .. & $\ldots$ & ror & Unmar. & & - & - \\
\hline Fanny Gore ... & . & 101 & Harry Pitt ... & $\ldots$ & 163 & 223 \\
\hline
\end{tabular}

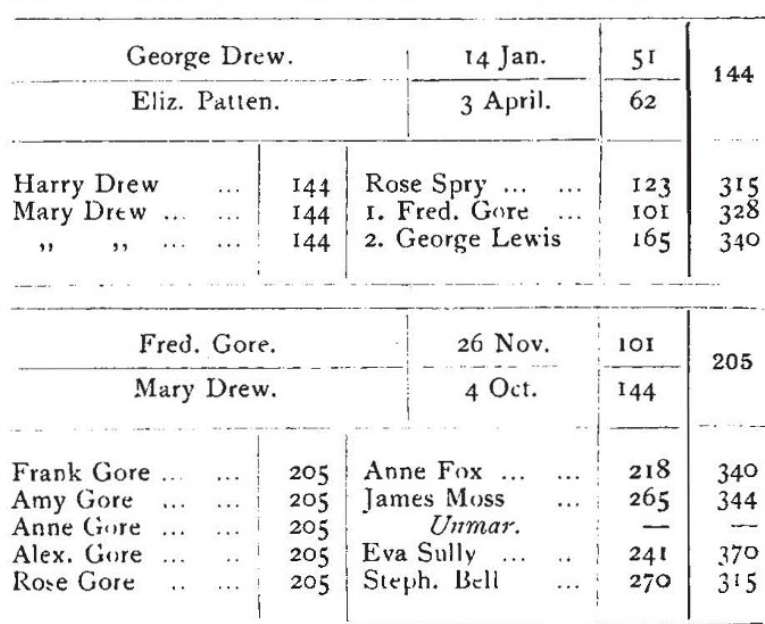

only half a line being allotted to each individual. In reality, a short paragraph of full-length lines would be used, to admit of the entry of long names, and of such details as are commonly inserted in pedigrees. Taking group 205 as our subject for explanation, it will be observed that each of the five members of the fraternity-Frank, Amy, Anne, Alex. and Rose. - -bear the same register No. of 205, which defines that group. The justification for indexing them in. the same group lies in the solidarity of each fraternity, 
all its members having the same parents, grandparents, uncles and aunts, and every other ascending or collateral relationship. It is not strictly so as regards descent, because the children of each brother or sister are nephews or nieces to all the others, but this material exception leads practically to no confusion. A fraternity is, therefore, treated as a compound unit, the individuals who form it being distinguished by their several names. Thus Rose Gore, 205, serves as a complete definition of her. The husbands and wives of the fraternity 205 belong severally to fraternities of their own, the numbers of which are attached to their names; thus the husband of Rose Gore, 205, is Stephen Bell, 27o. Her father, Fred Gore, belongs to group IOI, and her mother, Mary Drew, to group I 44. Both of these latter groups are printed here. Each parental couple heads a new group; thus, Fred. Gore, IOI, and Mary Drew, I44, combine to form the head of the new group 205. Similarly, Rose Gore, 205, and Stephen Bell, 27o, form that of the new group 315. It must be clearly understood that there is no relation between these numbers as such; they indicate no more than the No. of the page on which the new group happens to be entered. Every individual who is married and has children is entered in at least three different family groups, (1) that of his own fraternity, (2) in that of his wife, (3) in that in which he appears as one of the parental couple. If he marries a second time and has children, his name will appear as a parent in a fourth group, thus Mary Drew, 144, is entered as mother in each of the two groups 328 and 340 . It will be noticed that the day and month of birth is added to the name of each parent. This is a useful distinction in some Welsh and Scotch pedigrees where the same names repeatedly occur. It is a distinction of great efficacy, as the chance against a namesake having the same birthday is about $36_{5}$ to $\mathrm{r}$. If so, the chance against a namesake couple having the same birthdays as the couple in question would be $36_{5} \times 36_{5}$, or upivards of 130,000 , to $\mathrm{I}$.

Employment of the Tables.-Let us follow out the relationships of Frank Grore, 205, as far as these three tables permit. His father, as we know, is Fred. Gore, ror. Referring to ror, we see that his paternal grandfather and grandmother are John Gore, 3I, and Amy Myers, 43, respectively, so we should have to refer to the family groups $3 \mathrm{I}$ and 43 , which are not given here, to know more about them and their own near relations. We see that Frank Gore, 205, has two paternal uncles, George and Stephen; George married Jane Boyle, I36, and has the children described in 2 II ; Stephen is unmarried. Frank has also three paternal aunts, Ellen, Susan and Fanny; the second unmarried, Ellen married to John Piers, who has children in 237 , and Fanny married to Harry Pitt, $16_{3}$, who has children in 223. Jane Boyle's immediate relations are to be found in 136 , those of John Piers in 237, and those of Harry Pitt in 163 . The fraternities 211,237 and 223 exhaust the list of Frank Gore's first cousins on the paternal side. The group I 44 enables an equally complete analysis to be made on the maternal side. We can proceed in this way step by step as far as material exists. Intermarriages create no difficulty. The extreme confusion that arises from the ambiguous words of uncle, aunt, cousin, \&c., is wholly eliminated by this method of working, also that which is due to halfblood relationships.

It should be remarked that information is usually to be obtained with ease concerning any particular family group, because a knowledge of its details is shared by many persons. The father and the mother each know, of course, the names of their own children, and of those to whom they are married, in all but very exceptional cases. Similarly each brother and sister knows the full Christian name of his father and mother, and the mother's maiden name also, as well as the names and order of birth of his or her own brothers and sisters. This same knowledge is usually shared by the brothers- and sisters-in-law.

This method of fraternal unities and of family groups may be applicable to experiments in breeding animals and plants, but with modification of detail appropriate to each case. Where the breeding season is brief, the birthday would be of small distinctive value, even when the year of birth is added to it.

Francis Galton.

\section{STANDARDISATION.'}

THE first two publications referred to below are the first direct outcome of the work of the Engineering Standards Committee; the third is very intimately connected with that work.

The committee was appointed nearly two years ago, and owes its origin to the councils of the five great technical engineering societies acting on the suggestion of the council of the Institution of Mechanical Engineers.

Its existence is a symptom of the times, an indication of the fact that English engineers have grasped the importance of scientific cooperation and the necessity for organisation on a scientific basis.

The main committee consists of fourteen representatives of the five societies, leaders in the various engineering industries which they represent, and these have called to their assistance seven or eight sectional committees and a number of subcommittees to advise on special points. Representatives of the tecl nical Government departments serve on many of these, and the movement has the support of the-leading manufacturers. The work has grown and is growing; investigations of various kinds are needed to elucidate doubtful points before the committees can finally report; some of these are in progress at present at the National Physical Laboratory and elsewhere, and many men are working in a manner unknown before to strengthen English industry and to enable it to compete on favourable terms with foreign rivals.

Some months since it was announced that the committee dealing with steel structures was prepared to reduce considerably the number of sections to be rolled as a regular thing and stocked by the manufacturers, and the list it has proposed has just been issued. The committee is to be congratulated on its work. In all cases there has been great reduction and simplification, a result which will lessen the cost of production by reducing the number of rolls required, and will quicken the rate of supply by permitting stocks to be kept on hand. Thus it appeared that some forty-nine or fifty sizes of beams were in common use; these have been reduced to thirty; while for channels, in place of sixty-three, there are to be twenty-seven sizes rolled.

The recommendations as to rails have not yet been finally issued; at present there are seventy-three different sizes of tramway rails rolled; it is hoped to reduce these to five.

Messrs. Dorman Long and Co.'s new list referred to above is based on these standard sizes, of which a large supply is kept in stock at their various depots. The list gives, in addition to the dimensions and weight of the beams, various other data of importance, e.g. the moments of inertia about certain axes, and the safe distributed load for spans of various lengths.

1 British Standard Sections issued by the Engineering Standards Committee.

British Standard Beams. (Dorman Long and Co.

Standard Sizes of Conductors. (Cable Makers' Association. 